\title{
Application of a compact automatic sea water sampler to high frequency picoplankton studies
}

\author{
Stéphan Jacquet*, Jean-François Lennon, Daniel Vaulot \\ Station Biologique, CNRS, INSU et Université Pierre et Marie Curie, BP 74, F-29682 Roscoff cx, France
}

\begin{abstract}
This note describes a compact automatic sampler designed to collect small water samples (about $3 \mathrm{ml}$ ) at high frequency (minutes to hours), which is very useful for marine microbial data acquisition. The device consists of a microprocessor card controlling, through an interface and a BASIC program, a fraction collector, a peristaltic pump and a set of tube-pinching electrovalves. Samples are kept at $4^{\circ} \mathrm{C}$ until analysis or fixation, which appears to result in minimal effects on parameters such as abundance, size or pigment fluorescence.
\end{abstract}

KEY WORDS: Automatic sampling · Picoplankton

Many dynamical phenomena need to be sampled at high frequencies, typically on the order of once per hour or more, because of their very tight entrainment to the daily scale. It is particularly true for the marine microbial community, in particular the photosynthetic picoplankton (cells smaller than $2 \mu \mathrm{m}$ ) that are ubiquitous and abundant in open oceanic areas (e.g. Li et al. 1992, Campbell \& Vaulot 1993). Recent studies have shown that these populations are highly synchronised and divide within a very short time window (Vaulot et al. 1995). Other parameters such as cell size or chlorophyll fluorescence are also characterised by short time scale variability, for example in response to high irradiance damage in surface waters (Stramska \& Dickey 1992a).

Recently, it has become possible to acquire high frequency time series data for bio-optical and physical parameters using in situ devices such as the Batfish (Herman 1985), the Undulating Oceanographic Recorder (Aiken \& Bellan 1986), the Multivariable Profiler or Moored Systems (Dickey 1988, 1991, Stramska \& Dickey 1992b). The latter constitute the best example of the effort made to increase the frequency of sampling

·E-mail: jacquet@sb-roscoff.fr. (up to a minute), allowing, for instance, a detailed understanding of dynamical changes in primary production (Dickey et al. 1991, Moline \& Prézelin 1997). Nevertheless, these techniques only collect information on bulk characteristics such as beam attenuation or stimulated chlorophyll fluorescence, and provide no detail on community composition and physiology. More classical sampling methods use discrete Niskin bottles linked to CTD (Conductivity, Temperature, Depth) profilers which are deployed during oceanographic cruises. However, the short time scale variability remains difficult to sample because of the necessary time intervals between profiles. In the best case, the maximum sampling frequency is every $2 \mathrm{~h}$. In addition, CTD profilers cannot be used when the ship is under way and remain restricted to fixed stations.

Simple and autonomous water collecting devices have rarely been described in the literature (Friederich et al. 1986, Abbott et al. 1990, Reed et al. 1997). This paper reports the design and capabilities of such a sampling and collecting device controlled by a microprocessor which was tested for laboratory culture sampling and used successfully in the field to collect sea surface water. The device is particularly useful for high frequency data acquisition of parameters which only require small water samples (i.e. 1 to $5 \mathrm{ml}$ ) such as those analysed using flow cytometry or epifluorescence microscopy.

Sampler design and implementation. The automatic sampler consists of a microprocessor card which controls, through a suitable interface and software, a fraction collector, a peristaltic pump and a set of tubepinching electrovalves (Fig. 1). With the exception of the pump, the device costs about US $\$ 300$ to build and requires about 100 man-hours to be built, excluding the conception phase. Full description of the mechanical and electrical circuits, as well as a sample control program, are available from the first author. 


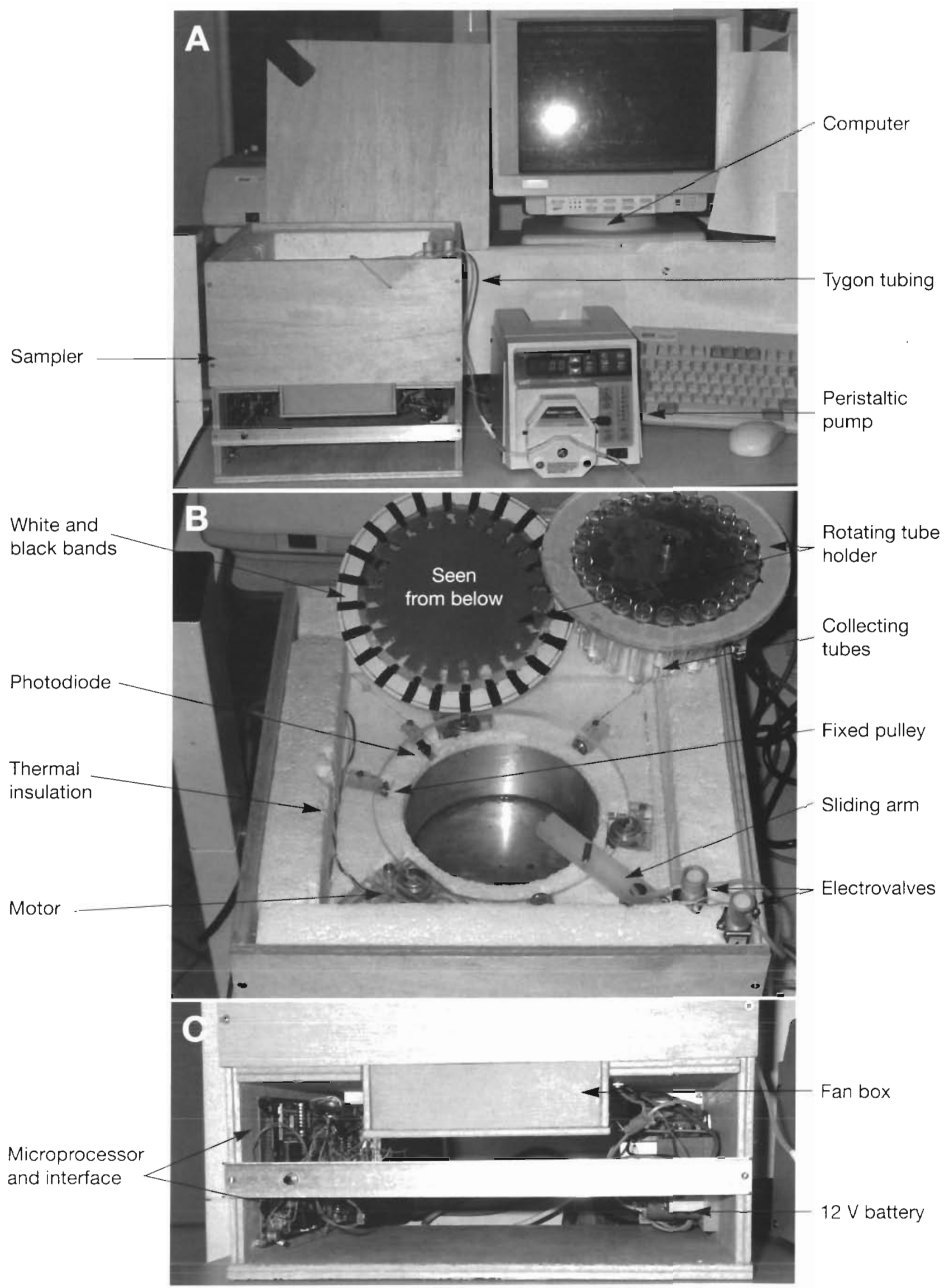


Fig. 1. (A) General view of the automatic sampling device, the peristaltic pump and the computer used to load the program into the microprocessor. (B) Detailed view from above, displaying the rotating disk with the white and black indexes recognised by the opto-coupler, the motors and the pulleys inducing the rotation, the electrovalves which direct the water flow through the tygon tubing to the collecting tubes or the waste (not shown). (C) Bottom part of the sampler, showing the location of the electrical controls (microprocessor, interface, battery) and the fan box

Microprocessor board: The system is controlled by a microcomputer board (see Anonymous 1987, p 24-31), built around the Intel $8052 \mathrm{AH}$ Basic microprocessor and its peripherals (mainly memory for programs and data). Programs, written in BASIC and stored in ASCII format on any PC-compatible computer, are sent to the microcomputer board through a RS-232 link by any communication software such as Telemate ( $T$. Hu, White River Software, Ontario, Canada). Programs can either be loaded and used in RAM (Random Access Memory), which is handy for debugging, or burned into an EPROM (Erasable Programmable Read Only Memory), making the device completely independent from an external computer once the program has been satisfactorily tested and sent by the microcomputer board. The 8 input/output lines of its paraliel port are directly controlled by a BASIC instruction (PORT1). A counter input (INT1) is also available. An input line reads the state of the photodiode monitoring the position of the sampler. Other lines, programmed as outputs, control respectively the rotation of the sampler, the state of the 2 electrovalves, the rotation of the pump and its direction (forward and reverse). The TTL (Transistor Transistor Logic) logic levels, provided by PORT1, can be used directly, for instance to control the pump, but sometimes have to be boosted using amplifiers, for example to control electrovalves or the motors of the sampler. Power can be provided either by a main line $(220 \mathrm{~V})$ when available or by a $12 \mathrm{~V}$ car battery, which can also automatically take over in case of main supply failure.

Fraction collector: This consists of a Perspex disk with 24 holes into which are inserted 24 hemolysis tubes $(75 \times 12 \mathrm{~mm}$, 4.5 ml, CML, Nemours, France, Figs. 1 \& 2). The disk is rotated by 3 gear box or step by step motors (Selectronic, Lille, France) pressing against the external circumference of the disk, $120^{\circ}$ apart, and is held in place by 3 fixed pulleys placed between the motors, $120^{\circ}$ apart (Fig. 2A). This design allows easy cooling of the sampling tubes in the tank below the disk (see below). The position of the disk is given by a photoelectric device consisting of a reflective opto-coupler (CNY70, Selectronic), providing isolation between input and output. The photodiode detects the presence of black and white indexes drawn on the reverse face of the disk (Fig. 2C). Motors stop running whèn meeting a black band, corresponding to the position of a tube, and resume as soon as the photodiode detects a white band.
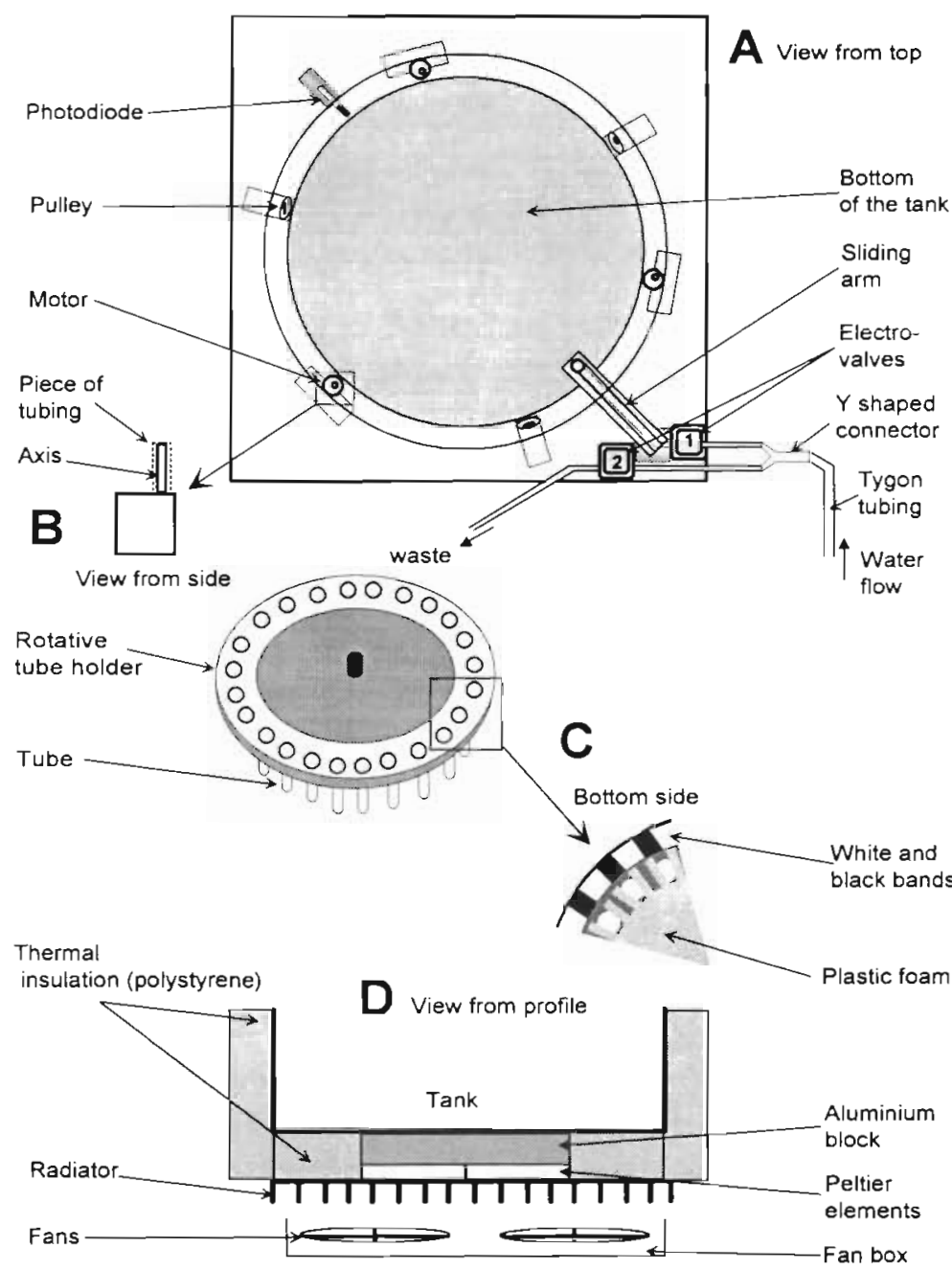

Fig. 2. (A) Schematic top view with tubing connection. (B) Motor with a piece of tubing inserted onto its axis. (C) Rotating disk with the white and black.bands and the plastic foam that maintains the tubes in place

(D) Schematic representation of the thermal regulation and insulation 
Thermal regulation: To refrigerate the tank, thermal regulation is achieved by means of 2 Peltier thermoelectric elements (Thermoelectricidad, Bertotza SL, Navarra, Spain) in line (capacity of $50 \mathrm{~W}$ each) supplied with the $12 \mathrm{~V}$ power source. In the bottom of the tank, a heat sensor allows measurement (after appropriate calibration) and regulation of temperature by means of a comparator with hysteresis (around $0.5^{\circ} \mathrm{C}$ ). Temperature data induce the switching of a relay acting on the Peltier modules. The bottom of the collector tank as well as the heat radiator largely overlap the size of the Peltier modules $(5$ by $10 \mathrm{~cm}$ ). The radiator, made of aluminium and directly in contact with the thermoelectric elements, acts as a heat exchanger. The heat is evacuated by means of an air flow generated by a couple of fans (Fig. 2D) placed in a box (Fig. 1C). Such a design allows the tank to be rapidly refrigerated with or without water in the tank (not shown).

Hydraulic system: Any pump that can be remotely controlled can be used. Sample water is transported in Tygon tubing (ref. 6419-14, Bioblock, Illkirch, France), compatible with the Masterflex ${ }^{\circledR}$ pump we used (ref. $7518-10$, Bioblock), and is separated into 2 parts by a $\mathrm{Y}$-shaped connector (Fig. 2A): one part, $10 \mathrm{~cm}$ in length, goes to the collector, whereas the other is connected to a waste container. Two pinching microelectrovalves (ref. 692901, 692904, Bioblock) are placed on each piece of tubing in order to guide the water flow and to get rid of dead volumes (Fig. 2A).

Software: The software allows the operator to define the sampling interval and the volume of the sample to be taken. If necessary, a 2 -stage pumping can be used with a high throughput pump delivering water continuously from the sampling location to a container from which samples are then taken. For example, during the Minos cruise, a ship pump continuously delivered sea surface water to a large bucket on the deck, and then our device sampled from that bucket.

Tests of sample preservation: Tests of sample fixation and storage were made with the 2 photosynthetic prokaryotes Prochlorococcus (strain MED4) and Synechococcus (strain WH 8103). Cultures were sampled while in exponential growth phase under a $12: 12 \mathrm{~h}$ light:dark cycle $\left(25 \mu \mathrm{E} \mathrm{m}^{-2} \mathrm{~s}^{-1}\right)$. Samples were taken every $1 \mathrm{~h}$ over $9 \mathrm{~h}$ including the afternoon, when the cell cycle varies the most (S. Jacquet unpubl.). We compared the effect of cold preservation with immediate analysis or immediate fixation (for cell cycle). The temperature was controlled by plunging the tubes into cold water refrigerated at $4^{\circ} \mathrm{C}$ by means of a freezing bath with external circulation (Minichiller, Bioblock), Samples kept at $4^{\circ} \mathrm{C}$ were analysed $10 \mathrm{~h}$ after the beginning of the experiment, following the chronology of the sampling, i.e. the last samples were kept at $4^{\circ} \mathrm{C}$ for a maximum of only $4 \mathrm{~h}$ before analysis.
Time series examples: Laboratory culture of Synechococcus ROS 04 (a strain isolated in Roscoff waters, France, $48^{\circ} 7^{\prime} \mathrm{N}, 3^{\circ} 9^{\prime} \mathrm{W}$ ) were grown under a $12: 12 \mathrm{~h}$ light:dark cycle $\left(25 \mu \mathrm{E} \mathrm{m}^{-2} \mathrm{~s}^{-1}\right)$. Samples were collected with the device every $15 \mathrm{~min}$ and analysed by flow cytometry. During the MINOS cruise, which sailed between Heraklion (Crete, Greece) and Toulon (France) in June 1996, more than 850 surface water samples were collected by the device, roughly every $30 \mathrm{~min}$, and analysed fresh by flow cytometry on board the ship (D. Vaulot, D. Marie, F. Partensky \& S. Jacquet unpubl.).

Results and discussion. Sample preservation by low temperature: In many cases, samples cannot be immediately processed (i.e. analysed or preserved). It is therefore critical to establish that sample parameters are little affected. For flow cytometry analyses, the best solution appears to be to keep the populations at $4^{\circ} \mathrm{C}$ in the dark without fixative addition. No significant difference for most parameters, measured by flow cytometry, was recorded between this protocol and immediate analysis for both Prochlorococcus and Synechococcus (Table 1). Only the Right Angle Light Scatter (a function of both cell size and refractive index) of Prochlorococcus MED4 looks more sensitive to cold conditions than that of Synechococcus WH 8103, suggesting a decrease in cell size and/or change in refractive index for the former strain. These results are in agreement with those of Olson et al. (1990) who maintained field water samples at $5^{\circ} \mathrm{C}$ for a few days without significant cell loss

Time series examples: The sampling device proved very useful for laboratory and field studies. Fig. $3 \mathrm{~A}$ shows a time series obtained for the Forward Angle Light Scatter (FALS), a function of cell size, for the marine cyanobacterium Synechococcus ROS 04 under a light:dark regime. A diel rhythm is clearly present. The high frequency of sampling permits precise location of features such as the timing of the FALS maximum, which occurs $3 \mathrm{~h}$ before darkness, and enabled

Table 1 . Effect of $4^{\circ} \mathrm{C}$ preservation protocol on cell abundance and flow cytometric parameters for Prochlorococcus (strain MED4) and Synechococcus (strain WH 8103). Data correspond to the average ratio (preserved control) of 10 measurements. RALS: right-angle light scatter

\begin{tabular}{lcc|} 
Parameter & $\begin{array}{c}\text { Prochlorococcus } \\
\text { ratio }\end{array}$ & $\begin{array}{c}\text { Synechococcus } \\
\text { ratio }\end{array}$ \\
\hline Cell abundance & 1.02 & 1.00 \\
RALS & 0.93 & 0.98 \\
Chlorophyll fluorescence & 0.99 & 1.01 \\
Phycoerythrin fluorescence & - & 1.01 \\
Percentage of cells in G1 & 0.97 & 1.00
\end{tabular}



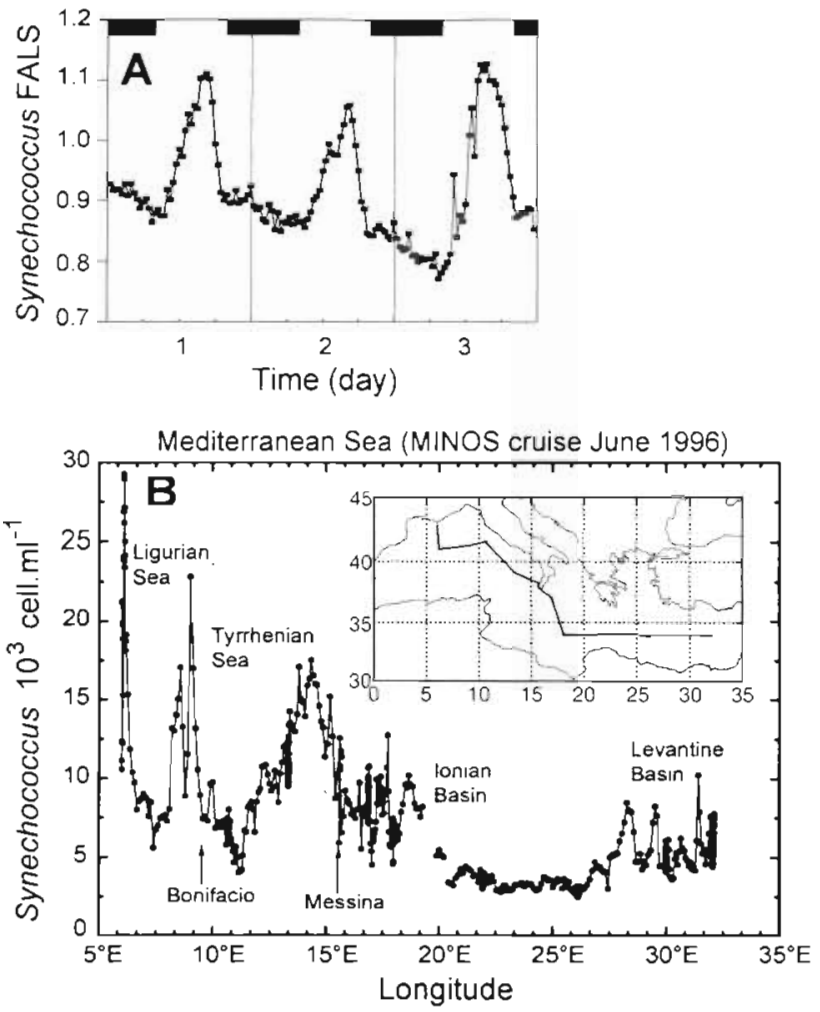

Fig. 3. (A) Time series of Synechococcus FALS obtained from laboratory culture. Dark bars symbolise the dark period of the day. (B) Synechococcus cell concentration determined by flow cytometry every $30 \mathrm{~min}$ in surface waters of the Mediterranean Sea on a transect between Toulon (France) and Heraklion (Crete) during the MINOS cruise (French vessel

NO 'Le Suroit', June 1996). Number of samples is 876

us to determine that the rate of FALS increase during the day was quicker than its decrease during the night. Clearly, these features would have been missed with lower frequency sampling. The device was also used during the Mediterranean cruise MINOS (Fig. 3B). This allowed us to map precisely the basin-scale features of Synechococcus abundance throughout both western and eastern Mediterranean basins (e.g. note the very low concentration in the oligotrophic Eastern Basin) and also to detect mesoscale features in the Ligurian Sea or Levantine Basin. To our knowledge, it is the first time that such high resolution spatial data are available for an individual phytoplankton population.

Concluding remarks: Advantages of the system described in this paper are numerous. First, its small size and compactness make it very convenient to transport and position on board a ship. Second, its simple design makes it very cheap to build (almost a tenth of the price of commercial devices which range from US $\$ 2000$ to 5000 without refrigeration) and very easy to service and to repair, again an advantage for ship- board operation. Third, the use of the BASIC language makes it easy to program. Fourth, it is very flexible and can sample at any given time interval. The preservation protocol chosen, necessary to avoid the continuous presence of an operator near the instrument, i.e. sample preservation at $4^{\circ} \mathrm{C}$, proved very effective and results in minimum parameter change. Finally, it must be stressed that, although the samples could be analysed by any technique requiring small analytical volumes, flow cytometry is most appropriate because of its speed and accuracy. Many improvements are possible and include (1) the use of a different cooling system (for example, by circulating chilled water around the radiator from an external water-cooled bath), (2) the simultaneous measurements of external parameters such as light irradiance levels or temperature at the time of the sampling by means of sensors coupled to the multiplexer of the microprocessor or (3) the possibility of using a disk with larger holes and collecting tubes to sample larger volumes.

Acknowledgements. This work was supported by contract MAS3-CT95-0016 (MEDEA) from the European Commission, by JGOFS-France PROSOPE Program, and by a doctoral fellowship from the Ministère de la Recherche et de l'Enseignement Supérieur granted to S.J. We thank Antoine Sciandra for helpful comments about the device and Michael Rappé for critical reading and improvements of the final English version of the manuscript.

\section{LITERATURE CITED}

Abbott MR, Brink KH, Brooth BR, Blasco D, Codispoti LA, Nüler PP, Ramp SR (1990) Observations of phytoplankton and nutrients from a Lagrangian drifter off northern California. J Geophys Res 95:9393-9409

Aiken J, Bellan I (1986) Synoptic optical oceanography with the undulating oceanographic recorder. Proc SPIE Int Soc Opt Eng 637:221-230

Anonymous (1987) Basic computer. In: Segment BV (ed) Elektor Electronics, November, p 24-31

Campbell L, Vaulot D (1993) Photosynthetic picoplankton community structure in the subtropical North Pacific Ocean near Hawaii (Station Aloha). Deep Sea Res 40 2043-2060

Dickey $\mathrm{T}$ (1988) Recent advances and future directions in multidisciplinary in situ oceanographic measurements systems. In: Rothschild BJ (ed) Toward a theory on biological-physical interactions in the world ocean. Kluwer Academic, Dordrecht, p 555-598

Dickey $T$ (1991) The emergence of concurrent high resolution bio-optical and physical measurements in the upper ocean and their applications. Rev Geophys 29:383-413

Dickey T, Marra J, Granata T, Langdon C, Hamilton M Wiggert J, Siegel D, Bratkovitch A (1991) Concurrent high resolution bio-optical and physical time series observations in the Sargasso Sea. J Geophys Res 96:8643-8663

Friederich GE, Kelly PJ, Codispoti LA (1986) An inexpensive moored water sampler for investigating chemical variability. In: Bowman MJ, Yentsch CM, Peterson WT (eds) Tidal mixing and plankton dynamics. Springer-Verlag, New York, p 463-482 
Herman AW (1985) Biological profiling in the upper oceanic layers with a Batfish vehicle: a review of applications. In: Zirino A (ed) Mapping strategies in chemical oceanography. American Chemical Society, Washington, DC, p 293-314

Li WKW, Dickie PM, Irwin BD, Wood AM (1992) Biomass of bacteria, cyanobacteria, prochlorophytes and photosynthetic eukaryotes in the Sargasso Sea. Deep Sea Res 39: $501-519$

Moline MA, Prézelin BB (1997) High-resolution time series data for primary production and related parameters at a Palmer LTER coastal site: implications for modelling carbon fixation in the Southern Ocean. Polar Biol 17:39-53

Olson RJ, Chisholm SW, Zettler ER, Armbrust EV (1990) Pig-

Editorial responsibility: John Dolan,

Villefranche-sur-Mer, France ment, size and distribution of Synechococcus in the North Atlantic and Pacific Ocean. Limnol Oceanogr 35:45-48

Reed A, Carmichael A, De Angelis MA (1997) An inexpensive bottom water sampler. Cont Shelf Res 17:717-721

Stramska M, Dickey TD (1992a) Short-term variations of the bio-optical properties of the ocean in response to cloudinduced irradiance fluctuations. J Geophys Res 97 : 5713-5721

Stramska M, Dickey TD (1992b) Variability of bio-optical properties of the upper ocean associated with diel cycles in phytoplankton. J Geophys Res 97:17983-17887

vaulot D, Marie D, Olson RJ, Chisholm SW (1995) Growth of Prochlorococcus, a photosynthetic prokaryote, in the Equatorial Pacific Ocean. Science 268:1480-1482

Submitted: November 11, 1997; Accepted: January 27, 1998 Proofs received from author(s): February 26, 1998 